\title{
El rey, el emperador, el tirano: el concepto del poder e ideal político en la cultura intelectual alfonsina ${ }^{1}$
}

\section{The king, the emperor, the tyran: the concept of power and political ideal in the intellectual alphonsine culture}

\author{
Alexander MAREY \\ Facultad de Filosofía. National Research University \\ Higher School of Economics (HSE) \\ Moscú (Rusia) \\ fijodalgo@gmail.com / amarey@hse.ru
}

Recibido: 3 de febrero de 2014

Aceptado: 31 de marzo de 2014

\section{RESUMEN}

En el articulo se analiza la concepción del poder desarollada por los juristas del Alfonso el Sabio en las Partidas. Tras un sistema de oposiciones se muestra una papel principal del rey como el jefe político y también espiritual del su reyno. Se nota también la distinción principal existente en la doctrina alfonsí entre el rey y emperador: el poder del primero tiene un carácter místico, mientras que el de segundo se basa sobre los fundamentos puramente racionales.

PALABRAS CLAVE: Alfonso X, teología política, Siete Partidas, poder real, poder imperial, corpus político.

\begin{abstract}
The subject of this article is the concept of power developed by the jurists of Alfonso the Wise in the Partidas. The main role of the king as the political and spiritual leader of his Kingdom is shown through a system of oppositions. The existing main distinction between the king and emperor is also seen in the alphonsine doctrine: the power of the former has a mystical character, while the second is based on purely rational grounds.
\end{abstract}

KEYWORDS: Alfonso X, political theology, Partidas, royal power, imperial power, political corpus.

\section{RÉSUMÉ}

Analyse du concept de pouvoir développée par les juristes du roi Alfonso le Sage dans les Partidas. Le rôle principal du roi comme le chef politique et spirituel de son Royaume est représenté grâce à un système d'oppositions. La distinction principale existante est également visible dans la doctrine alphonsine entre le roi et l'empereur: le pouvoir du premier a un caractère mystique, tandis que le pouvoir de l'empereur est fondée sur des motifs purement rationnels.

MOTS CLÉ : Alfonso X, théologie politique, Partidas, pouvoir royale, pouvoir impériale, corpus politique. 
1. El siglo XIII fue la época clave para el desarrollo de una teoría propiamente europea del poder. Por un lado, la construcción tripartita del discurso sobre el poder, que fuera formulada por santo Tomás de Aquino en su Comentario a la Epistola a Romanos de san $\mathrm{Pablo}^{2}$, colocó el punto final a la exégesis del famosísimo pasaje de éste ultimo ${ }^{3}$. El paso siguiente en la formación de la concepción del poder fue posible sólo después de la introducción por Duns Escoto (1266-1308) de la dicotomía entre potestas ordinata y potestas absoluta Dei y de su aplicación en el cuadro político por W. de Ockham (1288-1347). Por otro lado, en el mismo período, gracias a la densa tradición de los specula principum ${ }^{4}$, fue formada la imagen del rey ideal contrapuesta a la del tirano y, a veces, a la del emperador.

En ese contexto, la producción jurídico-ideológica del scriptorium del rey León y Castilla Alfonso X el Sabio (1252-1284) ocupa un lugar especial. Nos referimos principalmente al corpus de derecho conocido como Las Siete Partidas, pero es posible extender el análisis sobre la concepción política del rey Sabio a otros de sus tex-

${ }^{1}$ El estudio se ha realizado al amparo de los proyectos de investigación $\mathrm{N}^{\circ}$ 13-03-00181 de la fundación Rusa Estatal para las Humanidades (RFH, www.rfh.ru)/Traducción comentada y estudio preliminar de las Siete Partidas del rey D. Alfonso el Sabio /, y No 14-09-0210 de HSE / Cofinanciación de los proyectos de RFH.

${ }^{2}$ S.Th. Super Rom. 13.1: Ad hoc dicendum est, quod regia potestas, vel cuiuscumque alterius dignitatis potest considerari quantum ad tria. Uno, quidem modo quantum ad ipsam potestatem, et sic est a Deo, per quem reges regnant, [...] ut dicitur Prov. VIII, 15. Alio modo potest considerari quantum ad modum adipiscendi potestatem, et sic quandoque potestas est a Deo [...] Quandoque vero non est a Deo sed ex perverso hominis appetitu, qui per ambitionem, vel quocumque alio illicito modo potestatem adipiscitur.[...] Tertio modo potest considerari quantum ad usum ipsius: et sic quandoque est a Deo, puta cum aliquis secundum praecepta divinae iustitiae utitur concessa sibi potestate [...] Quandoque autem non est a Deo, puta cum aliqui potestate sibi data utuntur contra divinam iustitiam [...].

Un análisis detallado de la teoría política del Aquinate y, sobre todo, de su concepción del poder se puede encontrar en este estudio monográfico: J. Finnis, Aquinas. Moral, Political and Legal Theory, N.Y., 1998, pp. 219-294.

${ }^{3}$ Rom. 13:1: omnis anima potestatibus sublimioribus subdita sit non est enim potestas nisi a Deo quae autem sunt a Deo ordinatae sunt.

Sobre la tradición medieval del comentario exegético de este fragmento véase: Ph. Buc, L'ambigüité du livre. Prince, pouvoir et peuple dans les commentaires de la Bible au Moyen Âge, Paris, 1994.

${ }^{4}$ Entre la abundante bibliografía sobre los textos de este género, cabe nombrar los trabajos siguientes: S. Bagge, The Political Thought of the King's Mirror, Odense, 1987; R. Darricau, «Miroirs des princes», Dictionnaire de spiritualité: ascétique et mystique, doctrine et histoire, IV, Paris, 1979, pp.1025-1632; A. De Benedictis, A. Pisapia, eds., Specula principum. Frankfurt am Main, 1999; y, en referencia particular a la realidad español I. Nanu, La «Segunda Partida» de Alfonso X el Sabio y la tradición occidental de los «specula principum». Ph.D. Dissertation, Barcelona, 2013.

${ }^{5}$ En este trabajo sigo la tradición antigua de atribuir al rey Sabio el fruto de los esfuerzos del grupo de redactores que encabezó. Según Francisco Elías de Tejada, «bien cabe hablar indistintamente del rey y de sus colaboradores, personificando en Alfonso X un movimiento que va, sin duda, más allá de su propia vida...» (Fr. Elias de Tejada, Historia de la literatura política en las Españas, vol. 2. Madrid, 1991, p. 73). 
tos jurídicos, como por ejemplo el Fuero Real o el Espéculo de las leyes. Según el punto de vista tradicional, Alfonso X, elaborando su doctrina del poder real, reunió en dos líneas ya mencionadas de la teoría política medieval. La primera, proveniente del santo Tomás; la segunda, de los specula principum. Pero en este caso, la dicotomía citada me parece insuficiente, porque no alcanza para concentrar toda la riqueza del ideario político-teológico alfonsí. En rigor, considero que para poder interpretar correctamente el ideal político alfonsí es necesario utilizar una tercera doctrina, la cual se encuentra en la obra De civitate Dei, que fue perfectamente conocida por Alfonso X, tanto de manera directa, como también a través de los Libri Ethymologiarum de san Isidoro.

El ideal alfonsí del rey puede ser comprendido e interpretado en toda su complejidad por medio de un sistema de oposiciones binarias: rey / pueblo; rey / tirano; rey / emperador. Antes de profundizar en estos aspectos, debemos detenernos someramente al menos en la concepción del poder real que podemos encontrar en el pensamiento alfonsí.

2. Puede parecer extraño que Alfonso $X$ no haya brindado ninguna definición del poder en los títulos de la Segunda Partida, dedicada al rey y a sus relaciones con el pueblo. En rigor, la encontramos en la Cuarta Partida, donde, en la tercera ley del título $17^{6}$, el jurista alfonsí discute todas las acepciones de la palabra latina potestas. Según esta ley, la palabra citada puede ser entendida en cuatro sentidos principales: como el dominio sobre el siervo, como la jurisdicción, como la autoridad que tiene el obispo sobre los clérigos de su obispado y, finalmente, como la patria potestas, el poder que poseen los padres sobre los hijos ${ }^{7}$.

Como se puede ver, en este fragmento el rey es considerado como el juez, y, en consecuencia, su poder es, esencialmente, judicial. Si bien, como es sabido, esta función constituye un elemento basal para la monarquía medieval, incluso la castellana ${ }^{8}$; para Alfonso el Sabio, esta función jurisdiccional no es única, ni tampoco la más importante. El mismo contenido y la interpretación de esa función en el texto alfonsí se

\footnotetext{
${ }^{6}$ Part. IV. III.17. Del poder que han los padres sobre sus fijos, de qual natura quier que sean.

${ }^{7}$ Part. IV.17.3: Tomase esta palabra, que es llamada en latin potestas, que quiere tanto dezir en romance como poderio, en muchas maneras. Ca a las vegadas se toma por señorio, assi como auiene en el poderio que ha el señor sobre su sieruo. E a las vegadas se toma por jurisdicion, assi como acaesce en el poder que han los Reyes, e los otros que tienen sus lugares sobre aquellos a que han en poder de judgar. E a las vegadas se toma por el poder que han los obispos sobre sus clerigos, e los abades sobre sus monjes, que les son tenudos de obedescer. E a las vegadas se toma esta palabra potestas, por ligamiento de reuerencia, e de subjecion, e de castigamiento, que deue auer el padre sobre su fijo.

${ }^{8}$ El desarollo de la idea «el rey-juez» en los siglos VIII-XII se puede hallar en el artículo clásico: A. Marongiu, «Un momento típico de la monarquía medieval: el rey juez», Anuario de Historia del Derecho español, XXIII, 1953, pp. 677-715; también cabe nombrar sobre el mismo tema el brillante estudio del profesor lucense Faustino Martínez Martínez, «Ecos cronísticos del Rey-Juez medieval», Cuadernos de Historia del Derecho, XVII, 2010, pp. 303-356.
} 
distinguen del modelo estandarte medieval. El rey alfonsí no aparece solamente como un juez ordinario, aunque y superior, pero sí como el criterio animado de la distinción entre el bien y el mal, como la regla viva del Derecho establecida por Dios ${ }^{9}$. Por eso todos los derechos y todas las leyes están debajo del rey, quien, de su parte, puede cambiarlos también como crearlos de nuevo y aún más puede realizar su potentia absoluta actuando fuera del orden jurídico existente, pasando los límites del mismo derecho también como de las sentencias judiciales ya promulgadas ${ }^{10}$. En este aspecto de la distinción entre bien y mal el poder del rey-juez, recibido directamente de Dios, cuyo vicario en la tierra es el rey ${ }^{11}$, está contiguo con su poder de legislador: el rey legisla en lo temporal como su Señor celestial lo hace en su Reino espiritual.

Cabe decir que la actividad legislativa fue entendida por Alfonso X como instrumento eficaz para la modificación del mundo o, quizá, de su regulación. Legislando, el rey en algún sentido, repetía las acciones de Dios, quien, en su tiempo, había creado este mundo y dio a los hombres sus leyes: vieja y nueva. En tal situación, la ley fue interpretada no como la «simple» norma procedente del hombre, sino como el establecimiento porque los homes sepan vivir bien y ordenadamente, segun el placer de $\operatorname{Dios}^{12}$; como el mandamiento que - y esto tiene una importancia esencial— «ordena las cosas $\rangle^{13}$. Creando las leyes, el rey ordenaba las cosas, i.e., creaba en la tierra una semejanza con el ordo divino, creado por Dios; y como Dios mostró a la gente el bien y el mal, también el rey por sus leyes muestra los yerros y la pena que corresponde a quien los cometa. De esta manera, el rey ideal alfonsí debe ser definido como el monarca absoluto, y su poder se constituye, en algún sentido, como el elemento que garantiza el orden terrestre.

\footnotetext{
${ }^{9}$ Part. II.1.6: Aun [...] los sabios [...] dixeron, que el rey tanto quiere dezir como regla, ca assi como por ella se conoscen todas las torturas e se endereçan, assi por el rey son conoscidos los yerros e emendados. ${ }^{10}$ FReal, IV.21.5: Non ha otro ome poder si non el rey de dar fidalgo por alevoso nin de quitalle de riepto sil non fuer provado aquello de que fue reptado; et maguer le sea provado, o sea judgado por alevoso, el rey le puede dar por quito e por leal, si tanta merced le quisiere facer: ca tan grant es el derecho del poder del rey, que todas las leyes e todos los derechos tiene so si; et el su poder non lo ha de los omes, mas de Dios, cuyo logar tiene en todas las cosas temporales.

Sobre el poder del rey de crear no solamente las leyes sino también las costumbres y usos vid. las leyes de los títulos Part. I.1-2; también se puede nombrar algunos textos de los últimos tres años: P. Miceli, Derecho consuetudinario y memoria. Práctica jurídica y costumbre en Castilla y León (siglos XI$X I V)$, Madrid, 2012; D. Panateri, Uso, costumbre y fuero en relación al discurso medieval de la Soberanía. Alfonso X el Sabio y la glosa de Gregorio López. Temas Medievales 20, 2012, pp.147-197; y aún más mi texto A. Marey, «Obyknovenie i obychay kak istochniki prava v kastilskoy pravovoy doktrine XIII veka (P.I.2)» («El uso y costumbre como las fuentes del Derecho en la doctrina jurídica del s. XIII»), Aequum ius. Ot druzey i kolleg k 50-letiyu professora D.V. Dozhdeva (Aequum ius: Homenaje al prof. Dmitry Dozhdev para sus 50 años), Moscú, 2013, pp. 78-94.

${ }^{11}$ El cargo del rey como vicario de Dios esta mencionado muchas veces en el texto de la Partida Segunda (Part. II.1.proem., 5-8, etc.) también en otros textos de alfonsíes, tanto normativos (Espéculo, el Fuero Real etc.), como también historiográficos (Estoria General, por ej.)

${ }^{12}$ Part. I.1.1

${ }^{13}$ Part. I.1.5
} 
3. El texto de Partidas, Primera y Segunda, establece dos definiciones distintas de pueblo. En la primera de ellas, se define al pueblo como la totalidad de gente del reino, en la cual se incluyen no sólo los laicos sino también los clérigos ${ }^{14}$. La segunda definición, también cuantitativa, subraya que para la existencia del pueblo son necesarios todos los sectores sociales de la población, desde los ricos hasta los pobres y menores ${ }^{15}$. Ninguna de esas definiciones implica el papel del rey en la vida de ese pueblo, aunque no hay duda de que su presencia es continua. En la primera de esas definiciones el pueblo es visto desde un punto de vista, se podría decir, de la jurisdicción del rey y, justo por eso, parece muy importante la inclusión de los clérigos en el cuerpo social. Esta norma concuerda con otra, de la Segunda Partida ${ }^{16}$, la cual establece la soberanía del rey sobre todos los asuntos, incluso los espirituales, y somete al rey la jurisdicción eclesiástica tanto como la seglar. Claro que Alfonso X no pretendió ni quiso entrar en conflicto abierto con la Santa Sede, usurpando el derecho de juzgar el clero. pero, ciertamente, suponía que dentro de los límites del reino la jurisdicción mayor debía pertenecer solamente al rey y a ningún otro ${ }^{17}$.

La segunda definición forma parte importante de la concepción alfonsina del pueblo. Si la primera tiene un papel auxiliar para la teoría de la jurisdicción absoluta del rey, la segunda entra en el título que muestra el pueblo como la unidad orgánica nutrida con el amor de su rey ${ }^{18}$. Ese amor tiene carácter recíproco y la procedencia orgánica, según la ley famosa de la Segunda Partida, de acuerdo con la cual el monarca es cabeza, corazón y alma de su pueblo ${ }^{19}$. El texto citado, de extrema importancia, general-

${ }^{14}$ Part. I.2.5: Pueblo tanto quiere decir como ayuntamiento de gentes de todas las maneras de aquella tierra do se allegan. E desto no sale home ni muger, ni clerigo, ni lego...

${ }^{15}$ Part. II.10.1: Pueblo llaman el ayuntamiento de todos los omes comunalmente, de los mayores, e de los medianos, e de los menores. Ca todos son menester, e non se pueden escusar, porque se han de ayudar unos a otros, porque puedan bien biuir, e ser guardados, e mantenidos.

${ }^{16}$ Se trata de una ley bastante conocida, donde Alfonso X, apelando al argumento histórico, afirma la primacía espiritual del rey como el sacerdote mayor de su reino:

Part. II.1.6: Segund dixeron los sabios antiguos e señaladamente Aristoteles en el libro que se llama Politica, en el tiempo de los gentiles el rey non tan solamente era guiador e cabdillo de las huestes e juez sobre todos los del reyno, mas aun era señor en las cosas espirituales $<\ldots>$ E porende los llamauan reyes, porque regian tambien el lo temporal como en lo espiritual.

${ }^{17}$ Es bien comprensible que esta pretensión del rey Sabio, como algunas otras, formó una parte de su interpretación de la afirmación famosa del Papa Inocencio III que ... Rex ipse superiorem in temporalibus minime recognoscat (X.IV.17.13). La interpretación alfonsina de esta máxima suponía de facto la existencia del poder absoluto del rey, incluso en los asuntos espirituales.

${ }^{18}$ Part. II.10. proem.: Comunaleza deue el rey auer a todos los del su señorio para amar e honrrar, e guardar a cada uno dellos, segun quel es, o el seruicio que del rescibe.

${ }^{19}$ Part. II.1.5: .. . Los santos dixeron que el rey es puedto en la tierra en lugar de Dios para complir la justicia e dar a cada uno su derecho. E porende lo llamaron corazon e alma del pueblo. Ca assi como yaze el alma en el corazon del ome, e por ella biue el cuerpo, e se mantiene, assi en el rey yaze la justicia que es vida e mantenimiento del pueblo de su señorio. E bien otrosi como el corazon es uno e por el reciben todos los otros miembros unidad, para ser un cuerpo, bien assi todos los del reyno, maguer sean muchos, porque el rey es, e deue ser uno, por esso deuen otrosi ser todos unos con el, para seruirle, e 
mente se considera como la recepción por Alfonso X de los ideas de Juan de Salisbury ${ }^{20}$ y, también, de santo Tomás de Aquino ${ }^{21}$. Juan de Salisbury en el texto del Policraticus, citando a Plutarco, afirma que el príncipe ocupa el lugar de la cabeza de su república ${ }^{22}$ mientras que el senado tiene el papel del corazón de ella ${ }^{23}$. Pero cabe decir que la definición alfonsina de pueblo tiene algunas diferencias muy significativas, las cuales no se pueden explicar por la recepción de las ideas del Salesberiensis.

Hablo, en primer lugar, del ya mencionado amor recíproco que deben tenerse el rey y su pueblo. La segunda cosa que cabe mencionar en este contexto es que el pueblo alfonsí, en efecto, se constituía como tal solamente en la unión con su rey. La necesidad del rey en la teoría política de Alfonso el Sabio tiene un carácter natural, porque sin el rey no puede existir el orden divino en la tierra. Así, la existencia del rey tiene un carácter necesario y esto se explica por dos razones: una de ellas responde al Derecho natural y la otra al Derecho divino. La necesidad natural del rey se muestra en las Partidas por los argumentos clásicos aristotélicos, según los cuales el hombre es nacido desnudo y privado de defensa natural, como las plumas, zarpas, los picos etc. Su única arma es el habla que le ayuda a comunicarse con otros ${ }^{24}$. Pero el ayuntamiento de los unos con los otros da, de un modo inevitable, comienzo a los conflictos multiples entre estos mismos porque las voluntades de los omes son departidas ${ }^{25} \mathrm{y}$, para resolver esos conflictos es necesario el rey, cuya función principal es juzgar y conciliar las partes. La segunda razón es más fácil de explicar para el jurista y el teólogo medievales. Como Dios, que es rex regum et dominus dominantium, es uno, también el rey, su vicario en la tierra, debe ser uno, ya que el orden social imita la armonía del orden divino.

ayudarle en las cosas que el ha de fazer. E naturalmente dixeron los sabios que el rey es cabeça del reyno, ca assi como de la cabeça nascen los sentidos por que se mandan todos los miembros del cuerpo, bien assi por el mandamiento que nasce del rey, que es señor e cabeça de todos los del reyno, se deuen mandar a guiar, e auer un acuerdo con el, para obedescerle, e amparar, e guardar, e acrescentar el reyno: onde el es alma e cabeça, e ellos miembros.

${ }^{20}$ Vid. ante todo el artículo de 2005: M. Kleine, «Os elementos do corpo político e a justiça nas Siete Partidas de Afonso X (1221-1284)», Politeia: Historia e Sociologia, 5 (1), pp. 103-118. y también la tesis doctoral de Irene Nanu ya mencionada: I. Nanu, op. cit., pp. 269-274.

${ }^{21}$ Para la análisis de las imágenes corporales en el tratado De Regno del Aquinate vid.: A. Morin, «Las referencias corporales en el De regno de Tomás de Aquino», Argos, 29, 2005, pp. 69-89; en parte el papel de la concepción de Aquinate para la teoría política alfonsina está mostrado en un estudio: J. López de Goicoechea, «La imago regis en las Partidas alfonsinas», Saberes. Revista de estudios jurídicos, económicos y sociales, 1, 2003, pp. 1-9, y en la tésis de I. Nanu.

${ }^{22}$ Policraticus, V.6: Sequitur ut eius imitantes vestigia de membris reipublicae dispiciamus. Dictum est autem principem locum obtinere capitis, et qui solius mentis regatur arbitrio.

${ }^{23}$ Ibid. V.9

${ }^{24}$ Part. II.1.7: ... Todas las cosas que son biuas, traen consigo naturalmente todo lo que han menester, que non conuiene que otro gelo acarree de otra parte. $<\ldots>$ Mas el ome de todo esto non ha nada para si, a menos de ayuda de muchos que le busquen, e le alleguen aquellas cosas que le conuienen.

${ }^{25}$ Part. II.1.7 
La tercera razón que también existe es que el rey, como ya se ha dicho, es la cabeza, el corazón y el alma de su pueblo. Formando con el pueblo una unidad orgánica, el rey no puede existir sin él y tampoco el pueblo puede vivir sin su rey. Por lo demás, se puede afirmar que sin el rey el pueblo puede ser considerado solamente como multitudo nomine populi indigna, usando las palabras de san Agustín; hablando de otro modo, el pueblo sin rey no tiene subjetividad, no puede ser estimado como el sujeto en sentido moral y jurídico. Esta colusión permite afirmar que la concepción alfonsina del pueblo está arraigada en la teología política de San Agustín, según la cual el pueblo es coetus multitudinis rationalis rerum quas diligit concordi communione socia$t u s^{26}$, la multitud unida por el acuerdo en algunas cosas queridas por todos los miembros de ésta. Es evidente que, no habiendo acuerdo explícito, la multitud no puede devenir pueblo como sujeto; es decir, como cuerpo o persona. En el caso alfonsí la cosa en que tienen que acordarse todos los de quienes consiste la multitud, es, sin duda, el rey que deviene, de tal modo, para el pueblo una columna vertebral, un ente vivificante, animante y razonante.

4. El problema de la tiranía y del derecho de los súbditos a la rebelión en la doctrina política alfonsí debe considerarse desde el contexto de la misma concepción corporal de pueblo y reino, desde las mismas posiciones agustinianas. Las tentativas de investigar este problema desde el otro punto de vista, aislándolo de los contextos corporales, están condenadas al fracaso.

Alfonso X define al tirano como a un rey o señor quien recibió el poder de modo ilegítimo, sea por fuerza o como resultado de alguna traición ${ }^{27}$, o, aunque primeramente fuera un monarca legítimo, después usó mal del su poder ${ }^{28}$. En esta definición se encuentran una conocida sentencia de Aristóteles, en la cual el tirano se define como un mal rey ${ }^{29}$, y otra, de santo Tomás, ya citada en este texto (Super Rom. 13.1), donde el gran teólogo describe las modalidades posibles de la obtención y de la utilización del poder ${ }^{30}$. El resto de la ley citada de las Partidas también está inspirada

\footnotetext{
${ }^{26}$ De civ. XIX.24.

${ }^{27}$ Part. II.1.10: Tyrano tanto quiere dezir como señor que es apoderado en algund reyno o tierra por fuerça o por engaño o por traicion. E estos atales son de tal natura, que despues que son bien apoderados en la tierra, aman mas de fazer su pro, maguer sea daño de la tierra, que la pro comunal de todos, porque siempre biuen a mala sospecha de la perder.

${ }^{28}$ Part. II.1.10: ... Otrosi dezimos que maguer alguno ouiesse ganado señorio del reyno por alguna de las dichas razones que diximos en la ley ante desta, que si el usasse mal de su poderio en las maneras que de suso diximos en esta ley, quel pueden dezir las gentes tyrano e tornarse el señorio que era derecho en torticero, assi como dixo Aristoteles en el libro que fabla del regimiento de las cibdades e de los reynos. ${ }^{29}$ Ethic. VIII.10, 1160b. Cfr.: S.Th. DRG. I.2: Si igitur regimen iniustum per unum tantum fiat qui sua commoda ex regimine quaerat, non autem bonum multitudinis sibi subiectae, talis rector tyrannus vocatur, nomine a fortitudine derivato, quia scilicet per potentiam opprimit, non per iustitiam regit: unde et apud antiquos potentes quique tyranni vocabantur.

${ }^{30}$ S.Th. Super Rom. 13.1: ... Alio modo potest considerari quantum ad modum adipiscendi potestatem, et sic quandoque potestas est a Deo $<\ldots>$ Quandoque vero non est a Deo sed ex perverso hominis ap-
} 
por el texto De regimine principum de santo Tomás. El tirano se describe como el señor preocupado por hacer la vida de sus súbditos tan mala como le sea posible, sembrando entre ellos la hostilidad y el miedo mutuo, matando a los fuertes, expulsando a los sabios, etc. ${ }^{31}$ Sin embargo, hay una diferencia bastante significativa entre las construcciones tomista y alfonsí: si el Aquinate presupone la oportunidad de la rebelión contra el tirano, aunque advierte del peligro de esa acción, Alfonso el Sabio no dice sobre el derecho a rebelión ni una palabra. Tal silencio debe ser explicado porque en la situación de la ausencia de las normas sobre el derecho a la rebelión la ley sobre la tiranía parece, por lo menos, insuficiente, si nos quedamos en el paradigma del pensamiento tomístico.

Así, Nieto Soria en su artículo «Rex inutilis y tiranía», después de marcar los indicios característicos de la tiranía en la doctrina política alfonsí, destaca la ausencia en los textos del monarca del problema de la actitud frente al tirano y afirma que «en esta ausencia donde acaso se pone de manifiesto lo que, de seguir la lógica planteada en materia de tiranía, hubiera podido conducir a soluciones poco convenientes para la ideología monárquica que sostenía todo el entramado ideológico de las Partidas.... $\rangle^{32}$. La joven investigadora de la Universidad de Valencia, Irina Nanu, considerando en las páginas de su tesis el mismo problema, marcó algunos puntos importantes y dignos de discusión que voy a comentar aquí. En el principio del capítulo dedicado a la tiranía en la concepción alfonsí la doctora Nanu dice: «Lejos de ser la expresión de un castigo divino, como sostenía la tratadística política influenciada por el ideario

petitu, qui per ambitionem, vel quocumque alio illicito modo potestatem adipiscitur. $<\ldots>$ Tertio modo potest considerari quantum ad usum ipsius: et sic quandoque est a Deo, puta cum aliquis secundum praecepta divinae iustitiae utitur concessa sibi potestate $<\ldots>$ Quandoque autem non est a Deo, puta cum aliqui potestate sibi data utuntur contra divinam iustitiam $<$... $>$.

${ }^{31}$ Part. II.1.10: ... Dixeron los sabios antiguos que usaron ellos de su poder siempre contra los de pueblo, en tres maneras de arteria. La primera es que estos atales punan siempre que los de su señorio sean necios e medrosos $<\ldots>$ La segunda es que los del pueblo ayan desamor entre si, de guisa que non se fien unos de otros $<. . .>$ La tercera es que punan de los fazer pobres e de meterles a tan grandes fechos que los nunca pueden acabar $<\ldots>$ E sobre todo siempre punaron los tyranos de estragar los poderosos e de matar los sabidores...

Cfr.: S.Th. DRG. I.4: ... Nec solum in corporalibus subditos gravat, sed etiam spiritualia eorum bona impedit, quia qui plus praeesse appetunt quam prodesse, omnem profectum subditorum impediunt, suspicantes omnem subditorum excellentiam suae iniquae dominationi praeiudicium esse. Tyrannis enim magis boni quam mali suspecti sunt, semperque his aliena virtus formidolosa est. Conantur igitur praedicti tyranni, ne ipsorum subditi virtuosi effecti magnanimitatis concipiant spiritum et eorum iniquam dominationem non ferant, ne inter subditos amicitiae foedus firmetur et pacis emolumento ad invicem gaudeant, ut sic dum unus de altero non confidit, contra eorum dominium aliquid moliri non possint. $<\ldots>$ Conantur etiam ne potentes aut divites fiant, quia de subditis secundum suae malitiae conscientiam suspicantes, sicut ipsi potentia et divitiis ad nocendum utuntur, ita timent ne potentia subditorum et divitiae eis nocivae reddantur.

32 J.M. Nieto Soria, «Rex inutilis y tiranía en el debate político de la Castilla bajomedieval», Coups d'État à la fin du Moyen Âge? Aux fondements du pouvoir politique en Europe occidentale (ed. por F. Foronda, J.P. Genet, \& J.-M. Nieto Soria), Madrid, 2005, pp. 73-92. 
agustiniano e isidoriano, la tiranía constituye, para los autores de la Segunda Partida, el resultado de una transgresión legal, que periclita la paz y la justicia, el bienestar social y la prosperidad económica $\rangle^{33}$. Algunas páginas más abajo, discutiendo el problema del derecho a la rebelión, ella añade que gracias, primeramente, al origen divino del poder y también a la transmisión irreversible del poder efectuada por el pueblo al rey, el primero perdió el derecho a resistir y tiene que vivir bajo el tirano y tolerar sus represiones ${ }^{34}$.

Es fácil notar que ambos investigadores en sus construcciones conceptuales toman como punto de referencia la imagen del rey elaborada por los juristas de Alfonso el Sabio y, comparándola con las teorías de Juan de Salisbury, de santo Tomás o de algunos autores posteriores al monarca castellano, llegan las semejantes conclusiones. Creo, por lo tanto, que tal punto de vista es poco oportuno para el análisis de la tiranía en la teoría política castellana del período alfonsí. La posición clave en este discurso debe ser presentada no por la definición del rey sino por la del pueblo y puedo afirmar con toda la seguridad que la lectura cuidadosa de ésta conduce a la interpretación correcta de todo el conjunto de las concepciones monárquicas del rey Sabio, i.e., de las concepciones de rey, tirano y también de emperador.

El pueblo, como ya se ha dicho antes, es considerado por Alfonso X como cuerpo, cuya cabeza, corazón y alma es su rey. Es decir, el monarca forma parte de su pueblo y no puede existir sin él, también el pueblo está orgánicamente ligado al rey. El tirano, como se dijo antes, en la concepción alfonsí se define como un mal rey que recibió su poder de modo incorrecto o, habiéndolo recibido correctamente, lo utiliza de mala manera. Lo más importante en esta definición es que el tirano es igualmente rey, un señor para su gente. El tirano no deja de ser el corazón, cabeza y alma de su pueblo, lo que hace absolutamente imposible cualquier tentativa de rebelión contra él. Es imposible que el cuerpo se subleve contra la tiranía de su cabeza, alma o del mismo corazón en este caso, como se entiende, el hombre o se volverá loco o, más bien, morirá, el pueblo se convertirá en una multitud. Las cualidades del monarca son determinadas por las cualidades del pueblo; citando las palabras de San Agustín, [populus] tanto utique melior, quanto in melioribus, tantoque deterior, quanto est in deterioribus concors (De Civ. XIX.24). Esto permite deducir que el mismo pueblo es responsable por su monarca, que confirma también san Isidoro, diciendo en las Sentencias que populi delictum est quando principes mali sunt (Sent. III.52.1).

Así, el tirano en la teoría alfonsí no aparece como un «anti-héroe» o como un personaje negativo, sino que forma parte necesaria de la imagen del monarca absoluto, quien, aunque abusa de su poder, todavía es la cabeza de su pueblo. El pueblo en este caso no tiene ninguna oportunidad de iniciar la rebelión contra su gobernante, porque, primero, está ligado a él por vínculos orgánicos y, segundo, es responsable él mismo

\footnotetext{
${ }^{33}$ I. Nanu, op. cit., p. 261.

${ }^{34}$ Ibid., pp. 271-272.
} 
por los pecados y perversiones del su rey-tirano. Esta teoría, coincide en algunos puntos con las construcciones teológico-políticas de un autor posterior al rey Sabio, profesor de la Universidad de Salamanca, Francisco de Vitoria, quien en su Relectio de potestate civile afirmó que la Res publica, habiendo creado el rey, le entrega su autoridad (auctoritas), mientras que el poder (potestas) el monarca lo recibe directamente de Dios. Si es posible imaginar que la Res publica, que tiene para Vitoria el mismo sentido que el pueblo para Alfonso X, no entrega la autoridad al rey o, por contra, le toma esta auctoritas, el rey lógicamente se convierte en tirano, que posee el poder divino pero no tiene la autoridad política.

5. La concepción alfonsí del poder imperial generalmente se describe basándose sobre las primeras cuatro leyes del $1^{\circ}$ título de la Partida Segunda ${ }^{35}$. En estas leyes, el emperador se representa como el poseedor de la más alta honra y el más noble poder, los cuales consisten en el derecho al mando supremo (la definición alfonsí de imperio) ${ }^{36}$. Su poder, además de ser el más noble de todos, tenía algunas características importantes, que cabe nombrar aquí.

Primero, el emperador puede legislar, i.e., crear las leyes nuevas, cambiar o derogar los fueros caducos y costumbres viejas y malas. También, lo que es importante, puede crear nuevas buenas costumbres en caso de necesidad ${ }^{37}$. En estas prerrogativas el poder del emperador coincide con el poder real, aunque existen algunas variaciones dignas de mención. Así, aunque el emperador puede escribir y promulgar las leyes nuevas y esclarecer las ya existentes, no tiene poder de hacer el derecho, que sí puede hacer el rey ${ }^{38}$. La explicación de esta diferencia, como parece, puede ser hallada en otras leyes de la misma Segunda Partida, en las cuales se dice que el emperador tiene el poder superior en las cosas temporales, mientras que en las cuestiones espirituales se somete a Papa ${ }^{39}$. El rey, por su parte, precediendo al emperador en sentido crono-

\footnotetext{
${ }^{35}$ Ibid.

${ }^{36}$ Part. II.1.1: Imperio es gran Dignidad, noble y honrrada sobre todas las otras que los omes pueden auer en este mundo temporalmente. Ca el señor a quien Dios tal honrra da es el rey, e emperador, e a el pertenesce, segund derecho, el otorgamiento que le fizieron las gentes antiguamente, de gouernar, e mantener el imperio en justicia. E por esso es llamado emperador, que quiere tanto dezir como mandador, porque al su mandamiento deuen obedescer todos los del Imperio, e el non es tenudo obedescer a ninguno, fueras ende el Papa en las cosas espirituales.

${ }^{37}$ Part. II.1.2: El poderio que el emperador ha es en dos maneras. La una es de derecho: e la otra de fecho. E aquel que ha segund derecho, es este que puede fazer ley e fuero nuevo, e mudar el antiguo, si entendiere que es pro comunal de su gente, e otrosi quando fuesse escuro, ha poder de lo esclarecer. $E$ puede otrosi toller la costumbre usada, quando entendiere que era dañosa, e fazer nueva, que fuesse buena.

${ }^{38}$ Part. II.1.6: ... Tomo el rey nome de Nuestro Señor Dios ca assi como el es dicho Rey sobre todos los reyes, porque del han nome, e los gouierna, e los mantiene en su lugar en la tierra, para fazer justicia e derecho...

Cfr. otrosí: Part. II.1.7; etc.

${ }^{39}$ Part. II.1.1.
} 
lógico ${ }^{40}$, le sobrepasa también en la capacidad de sus poderes, quedando como vicario de Dios en la tierra y, en efecto, ejerciendo su poder no sólo en lo temporal sino también en lo espiritual dentro de los límites de su reino ${ }^{41}$.

Además de la mencionada función legislativa, el emperador tiene el poder de fijar los impuestos, crear los portazgos y las ferias, designar los jueces y los adelantados de su imperio, ejercer el poder judicial, arreglar los asuntos diversos del su Imperio y, en el tiempo de guerra, encabezar su hueste y caballería, conduciéndolos a la victoria. En tiempo de paz el emperador aun puede establecer y cambiar las fronteras y los límites de las provincias y ciudades, dar los feudos, beneficios y privilegios ${ }^{42}$. Todos estos poderes los tiene también el rey, pero en una medida más grande, como se puede ver de las leyes de la Segunda Partida. Mientras que el emperador puede solamente tomar yantares e tributos, e censos en aquella manera que lo acostumbraron antiguamente ${ }^{43}$, el rey puede aumentar o disminuir los tributos o impuestos según su decisión. Mientras que el primero puede dar a otros castillos y villas del imperio solamente en las condiciones de la posesión feudal, el segundo bien puede dejar a sus vasallos los mismos objetos por heredad ${ }^{44}$. Por fin, mientras que el rey es el señor de todo su reino enteramente, también del pueblo, como de todas las cosas del mismo, y, por demás, tiene este señorio por derecho de sucesión, el emperador, según la definición elegante de los juristas alfonsíes, es el señor de toda la gente del imperio pero no lo es de las cosas de cada uno ${ }^{45}$.

\footnotetext{
${ }^{40}$ Part. II.1.7: ... Como quier que ante fablamos del emperador, por la honrra del Imperio, que del rey, pero antiguamente primero fueron los reyes que los emperadores.

${ }^{41}$ Part. II.1.6: ... En el tiempo de gentiles el rey non tan solamente era guiador e cabdillo de las huestes, e juez sobre todos los del reyno, mas aun era el señor en las cosas espirituales, que estonces se fazian por reverencia e por honrra de los dioses, en que ellos creyan. E porende los llamauan reyes, porque regian tambien en lo temporal como en lo espiritual.

Cabe notar también una distinción muy fina hecha por los juristas alfonsís entre el rey y el Papa: así, en las leyes mencionadas ellos llaman al rey «el vicario de Dios» destacando de tal modo el carácter directo de la transmisión del poder real; en este mismo tiempo en las leyes definientes el poder del apostóligo este último es llamado "el vicario de los apóstoles», como todos los otros obispos. Esta distinción, como parece, muestra bastante claramente las pretensiones cesaro-papistas del rey Alfonso.

${ }^{42}$ Part. II.1.2; Part. II.1.4.

${ }^{43}$ Part. II.1.2.
}

Vid. otrosí: Part. II.1.8: ... El emperador por ninguna cuyta que le venga non puede apremiar a los del imperio, que le den mas de aquello, que antiguamente fue acostumbrado de dar a otros emperadores, si de grado dellos non se fiziere.

${ }^{44}$ Part. II.1.8: ... El rey puede dar villa, o castillo de su reyno por heredamiento a quien quisiere, lo que non puede fazer el emperador, porque es tenudo de acrescentar su imperio e de nunca menguarlo: como quier que los podria bien dar a otro en feudo, por seruicio que le ouiesse fecho, o que le prometiesse de fazer por ello.

${ }^{45}$ Part. II.1.2: Maguer los romanos que antiguamente ganaron con su poder el señorio del mundo, fiziessen emperador, e le otorgassen todo el poder, e el señorio que auian sobre las gentes para mantener, e defender derechamente el pro comunal de todos, con todo esso non fue su entendimiento de lo fazer señor de las cosas de cada uno, de manera que las pudiesse tomar a su voluntad, sino tan solamente, por algunas de las razones que de suso son dichas. 
Estas y todas las otras distinciones que existen entre el poder del rey y el poder del emperador en la concepción política de Alfonso el Sabio pueden ser explicadas por dos consideraciones de importancia crucial, las cuales, en su turno, condicionan la tercera, de carácter deducible. Primero, como afirman las leyes de las Partidas, el poder real tiene carácter hereditario, mientras que el emperador recibe su poder por elección ${ }^{46}$, que, por supuesto, disminuye su valor a los ojos del rey castellano. Segundo, también ligado con lo precedente, consiste en que el emperador todo el tiempo tiene que ganar y, habiéndolo ganado, guardar el amor del pueblo porque puede perderlo ${ }^{47}$. El rey, en cambio, no tiene que hacer esto, porque su pueblo, como se ha dicho antes, tiene que amar a su rey todo el tiempo, ya que éste último es su corazón, alma y cabeza. Estas dos consideraciones permiten deducir que el emperador, en contraste con el rey, no forma parte del cuerpo y su poder, de ese modo, tiene un carácter puramente racional y carece del componente místico. Esta hipótesis se confirma con consideraciones de carácter filológico: en las leyes de las Partidas dedicadas al imperio y al poder del emperador, los juristas no han utilizado la palabra pueblo, cambiándolo por otros lexemas, tales como la gente o los omes del Imperio. Tanto la voz gente como hombres, no tiene aquel sentido corporal que posee en la teoría política alfonsí el pueblo. Por eso, el emperador, aunque tiene el poder superior en los asuntos temporales, como se ha mostrado antes, todavía cede ante el rey.

6. Pasando a las conclusiones voy a repetir aquí mis afirmaciones principales elaboradas en el presente artículo. Antes que nada hay que recordar que en el proyecto político alfonsí se plasman de modo orgánico las doctrinas teológico-políticas de procedencia agustiniana y tomista. En particular, la concepción del pueblo tiene un carácter puramente agustiniano, según el cual el pueblo es el conjunto de toda la gente del reino unida por el amor a su rey y a su tierra. En segundo lugar, cabe notar que esta doctrina ha sufrido la influencia de las teorías de Juan de Salisbury y, después, de santo Tomás, habiendo tomado de éstas la imagen del pueblo como un cuerpo y, en consecuencia, del rey como su cabeza, alma y corazón. Tener en cuenta las raíces agustinianas de la teología política de Alfonso el Sabio permite comprender mejor las concepciones de tiranía y poder imperial.

El tirano, a pesar de ser un mal gobernante, todavía es rey, i.e., sigue conservando todas las calidades cruciales del poder real, antes que nada, la unidad orgánica con

\footnotetext{
${ }^{46}$ Part. II.1.7: Aun demas, que el rey lo tiene por heredamiento, e el emperador por elecion.

Part. II.1.8: Ca los reyes non tan solamente son señores de sus tierras mientra biuen, mas aun a sus finamientos las pueden dexar a sus herederos, porque han el señorio por heredad, lo que non pueden fazer los emperadores, que lo ganan por elecion, assi como de suso diximos.

${ }^{47}$ Part. II.1.3: Otrosi dixeron los sabios que el mayor poderio e mas complido, que el emperador puede auer de fecho en su señorio, es quando el ama a su gente, e es amado della. E mostraron que se podria ganar e ayuntar este amor, faziendo el emperador justicia derecha ... $<\ldots>$ Aun dixeron que el emperador, maguer amasse su gente, e ellos a el, que se podria perder aquel amor por tres razones...
} 
su pueblo. El es cabeza, alma y corazón de su pueblo, aunque esta cabeza, alma y corazón se sientan mal y perjudiquen la salud del cuerpo. Esta esencia del tirano explica las sentencias radicales del «Libro de cien capítulos» tanto como la ausencia total del derecho a la rebelión. Es imposible pensar la rebelión del cuerpo contra su corazón o alma, porque en este caso, es evidente, se trata de un suicidio. Al contrario, el emperador no forma ninguna parte del cuerpo político, tampoco la gente del imperio forma el pueblo, el cuerpo místico y político. Sus funciones están limitadas solamente a los asuntos temporales, mientras que en los espirituales cede la soberanía al Papa. El rey, por contra, se presenta como el poseedor de la summa potestas dentro de los límites de su reino. Su potestas iurisdictionalis debe ser pensada no solamente como el poder de carácter puramente feudal sino como un herramienta universal de distinción entre el bien y el mal, actitud típica del alma, según la teología medieval. Aludiendo a uno de los últimos libros del profesor Dalmacio $\mathrm{Negro}^{48}$, se puede decir que Alfonso el Sabio en su teoría política establece los fundamentos de la estatalidad española de la Edad Moderna.

${ }^{48}$ D. Negro, Historia de las formas del Estado. Una introducción, Madrid, 2010. 


\section{BIBLIOGRAFIA CITADA}

BAGGE, S. The Political Thought of the King's Mirror, Odense, 1987.

BUC, Ph., L'ambigüité du livre. Prince, pouvoir et peuple dans les commentaires de la Bible au Moyen Âge, Paris, 1994.

DARRICAU, R., «Miroirs des princes», Dictionnaire de spiritualité: ascétique et mystique, doctrine et histoire, IV, Paris, 1979, pp. 1.025-1.632;

DE BENEDICTIS, A. PISAPIA, A. (eds.), Specula principum, Frankfurt am Main, 1999.

ELIAS DE TEJADA, Fr., Historia de la literatura política en las Españas, vol. 2, Madrid, 1991, p. 73.

FINNIS, J., Aquinas. Moral, Political and Legal Theory, N.Y., 1998, pp. 219-294.

KLEINE, M., «Os elementos do corpo político e a justiça nas Siete Partidas de Afonso X (1221-1284)», Politeia: Historia e Sociologia, 5 (1), pp. 103-118.

LÓPEZ DE GOICOECHEA, J., «La imago regis en las Partidas alfonsinas», Saberes. Revista de estudios jurídicos, económicos y sociales, 1, 2003, pp. 1-9.

MAREY, A., "Obyknovenie i obychay kak istochniki prava v kastilskoy pravovoy doktrine XIII veka (P. I.2)» («El uso y costumbre como las fuentes del Derecho en la doctrina jurídica del siglo XIII»), Aequum ius. Ot druzey i kolleg k 50-letiyu professora D.V. Dozhdeva (Aequum ius: Homenaje al prof. Dmitry Dozhdev para sus 50 años), Moscú, 2013, pp. 78-94.

MARONGIU, A., «Un momento típico de la monarquía medieval: el rey juez», Anuario de Historia del Derecho español, XXIII, 1953, pp. 677-715.

MARTÍNEZ MARTÍNEZ, F., «Ecos cronísticos del Rey-Juez medieval», Cuadernos de Historia del Derecho, XVII, 2010, pp. 303-356.

MICELI, P., Derecho consuetudinario y memoria. Práctica jurídica y costumbre en Castilla y León (siglos XI-XIV), Madrid, 2012.

MORIN, A., «Las referencias corporales en el De regno de Tomás de Aquino», Argos, 29, 2005, pp. 69-89.

NANU, I., La «Segunda Partida» de Alfonso X el Sabio y la tradición occidental de los «specula principum». Ph.D. Dissertation, Barcelona, 2013.

NEGRO, D., Historia de las formas del Estado. Una introducción, Madrid, 2010.

NIETO SORIA, J.M., «Rex inutilis y tiranía en el debate político de la Castilla bajomedieval», Coups d'État à la fin du Moyen Âge? Aux fondements du pouvoir politique en Europe occidentale (ed. por F. Foronda, J.P. Genet, \& J.M. Nieto Soria), Madrid, 2005, pp. 73-92.

PANATERI, D., «Uso, costumbre y fuero en relación al discurso medieval de la Soberanía. Alfonso X el Sabio y la glosa de Gregorio López», Temas Medievales 20, 2012, pp. 147-197. 